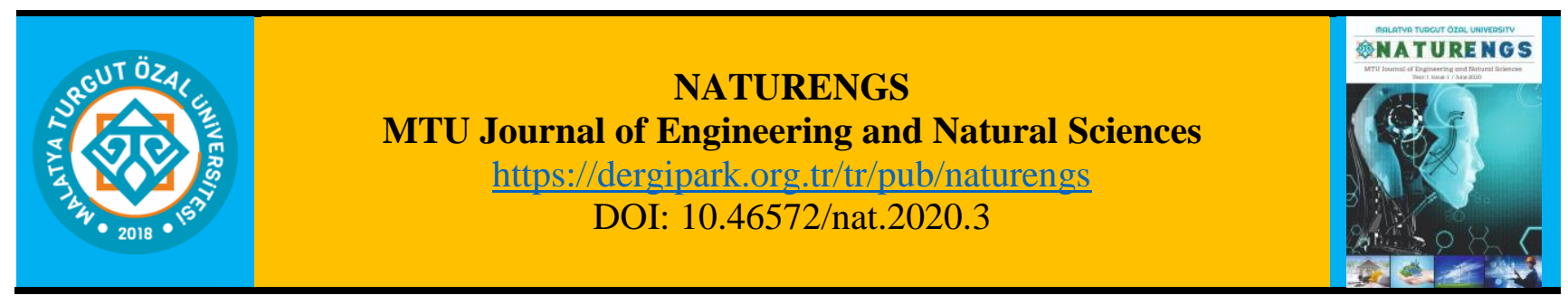

\title{
In Dynamic Systems with Fuzzy A - Cutting Determination of Membership Function Ranges
}

\author{
Fatih TOPALOĞLU ${ }^{1 *}$, Hüseyin PEHLIVAN ${ }^{2}$ \\ ${ }^{1}$ Department of Computer Engineering, Faculty of Engineering and Natural Sciences, Malatya Turgut Özal \\ University, Malatya, Turkey. \\ ${ }^{2}$ Department of Computer Engineering, Faculty of Engineering, Karadeniz Technical University, Trabzon, \\ Turkey.
}

(Received: 01.05.2020; Accepted: 10.05.2020)

\begin{abstract}
Uncertainties and inaccuracies in the membership function value ranges defined by the expert in dynamic systems cause serious errors in system output. In this study, the fuzzy $\alpha$-cutting technique was used to determine the ranges of membership functions on the universal cluster and neighborhood values of normal values were calculated for different $\alpha$ cutting coefficients and then neighborhood values were adjusted according to determined step values. Thus, while determining the value range of membership function in dynamic systems, it will be possible to talk about its neighborhood in the values that serve the same purpose. Operation in the dynamic process as wind power installation for Turkey wind energy interval value set in the potential atlas used and $\alpha$ cutting techniques of the gap on the universal set of the determined value with re-calculation and determination are provided.
\end{abstract}

Keywords: Dynamic systems, $\alpha$ - Cutting technique, Fuzzy cluster, Membership function.

\section{INTRODUCTION}

The concept of the fuzzy cluster was proposed by Zadeh in his classic article in 1962. Fuzzy sets and fuzzy logic provide methods and tools for accurate and precise data analysis and processing [1]. Fuzzy logic also has certain limits, and these limits vary depending on the situation. What distinguishes it from classical logic is that these limits are more flexible. Thanks to this flexibility, fuzzy logic gives much more sensitive results in every field it is applied [2]. Although the membership function value range is flexible, it is mostly determined based on the experience of the expert.

In fuzzy modeling, the correct determination of membership functions is of primary importance for the success of the model. It is possible to encounter many approaches in the literature about the selection of membership functions [3-15]. The fact that the value ranges that are close to the value determined in the approaches to determine the membership function value range also affects the system and has caused the need to be evaluated in the system at their neglected values. 
The method used for this need is the Fuzzy alpha cutting (FAC) technique. It is used to describe the uncertainty or error in the parameters of the FAC fuzzy set theory. Relations in the method can be extended to include fuzzy arguments. This principle can be used analytically in simple arithmetic operations. It is also used to perform arithmetic analysis at intervals [16].

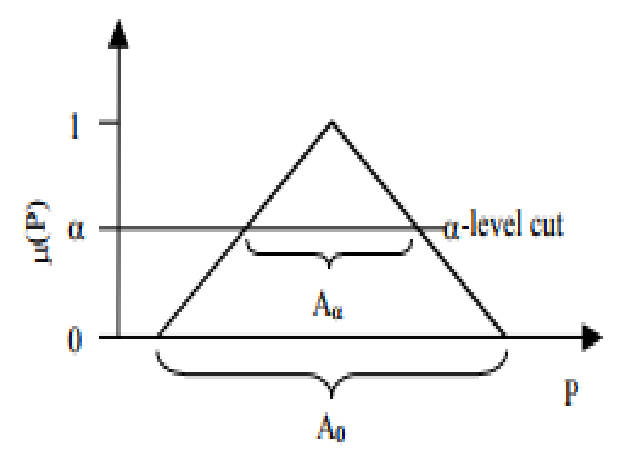

Figure 1. Fuzzy number support and cut

The membership function is truncated horizontally from a limited number of $\alpha$ levels from 0 to 1, as in Figure 1. The model is run to determine the minimum and maximum possible values of the output for each level of the parameter. This information is used to create the corresponding fuzziness of the outputs used as a measure of uncertainty [16].

The study, which required the installation of wind turbines wind speed, power density and capacity Electrical Power Resources Survey and Development Administration for meteorological parameters consisting of factors and the General Directorate of Meteorology Turkey wind energy potential atlas prepared by (REPA) with a range of over universal set of specified values It is provided to calculate and determine with $\alpha$-cutting technique.

In the article, firstly, mathematical equations that form the basis of $\alpha$ - cutting technique application are presented, then $\alpha$ - cutting technique application is applied to membership functions determined by expert experience. Finally, the new membership function value ranges are shown in the findings section.

\section{MATERIAL AND METHODS}

\subsection{Mathematical Infrastructure and Used Equations}

Mathematically, the fuzzy cluster is the assignment of a value that indicates the degree of membership to any entity in the discourse universe. The purpose of the fuzzy sets theory is to determine the degree of membership in the concepts to determine the uncertainty, which is difficult to define or difficult to define.

In classical set theory, an object is either an element of that set or not. Partial membership is not possible. If the object's membership value is 1 , it is the element of the set, and 0 is not the element. In fuzzy sets, an object is an element that determines a certain level of membership. 
Generally, the curve that changes according to the values of the elements of the set is called the membership function. In other words, the related characteristic function that has a value between $[0,1]$ created by the fuzzy set is the membership function. Accordingly, the membership level is the value of the change between 0 and 1 for each item. The fuzzy cluster theory developed by Zadeh assigns each object to some extent as a membership in a particular cluster [17].

Definition 2.1: If $A=\left[a_{1}, a_{3}\right]$ is in the value range, the membership function $\mu_{A}(x)$ can be shown as in equation 1 .

$\mu_{A}(x)=\left\{\begin{array}{cc}0, & x<a_{1} \\ 1, & a_{1} \leq x \leq a_{3} \\ 0 & x>a_{3}\end{array}\right.$

Definition 2.2: The relation used for the $\mu_{A}(x)$ triangle membership function is given in equation 2 and equation 3.

$\mu_{A}(x)= \begin{cases}0, & x<a_{1} \\ \frac{x-a_{1}}{a_{2}-a_{1}}, & a_{1} \leq x \leq a_{2} \\ \frac{a_{3}-x}{a_{3}-a_{2}}, & a_{2} \leq x \leq a_{3} \\ 0, & x>a_{3}\end{cases}$

$A_{\Delta}=\max \left(\min \left(\frac{x-x_{1}}{x_{T}-x_{1}}, \frac{x_{2}-x}{x_{2}-x_{T}}\right), 0\right)$

Definition 2.3: According to equation 2, set, $A=\left\{a_{1}, a_{2}, a_{3}\right\}$ is defined. a2 is considered a regular value membership. It is stated here that, depending on a $\alpha$ coefficient, it will have the same meaning as a2 value at values close to a2. In other words, the uncertainty in a 2 can be tolerated with a $\alpha$ coefficient to be determined. The specified neighborhood relationship is shown in Figure 2.

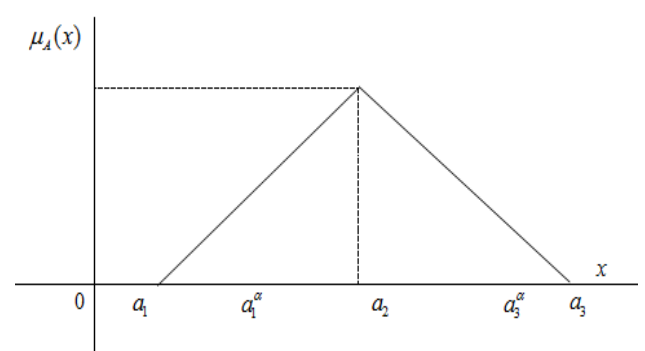

Figure 2. Neighborhood of numbers

Definition 2.4: In fuzzy logic applications, $\alpha$ value is defined as the cutting coefficient. The numbers $a_{1}^{\alpha}$ and $a_{3}^{\alpha}$ are the lower and upper limit values of the values assumed to have the same meaning as the a 2 value. $a_{1}^{\alpha}$ and $a_{3}^{\alpha}$ values can be found with the help of equations 4 and 5. 
$\frac{\mathrm{a}_{1}^{\alpha}-\mathrm{a}_{1}}{\mathrm{a}_{2}-\mathrm{a}_{1}}=\alpha$
$\frac{a_{3}-a_{3}^{\alpha}}{a_{3}-a_{2}}=\alpha$

Definition 2.5: For $\forall \alpha \in[0,1]$ from Equations 4 and 5, the $A_{\alpha}=\left[a_{1}^{\alpha}, a_{3}^{\alpha}\right]$ value range can be defined. The values of $a_{1}^{\alpha}$ and $a_{3}^{\alpha}$ can be calculated as in equations 6 and 7 .

$a_{1}^{\alpha}=\alpha\left(a_{2}-a_{1}\right)+a_{1}$

$a_{3}^{\alpha}=a_{3}-\left(a_{3}-a_{2}\right) \alpha$

Artificial neural networks, intuition, genetic algorithm, angled fuzzy cluster, and inference fuzzy logic are among the methods used to determine membership functions [18]. Membership functions used in fuzzy logic applications are trapezoid, triangle, Gaussian, S membership function, $\Pi$ membership function and bell curve membership functions [19].

\section{2. a-Cutting Technique Application}

In the study, the ranges of the membership functions prepared for the meteorological parameters that are planned to be used as input values in the installation of wind energy turbines on the universal cluster Meteorology General and Renewable Energy Office Headquarters located in Turkey wind atlas of Figure 3 is derived from five different topographical $50 \mathrm{~m}$ wind potential ranges of values are determined based on the height.

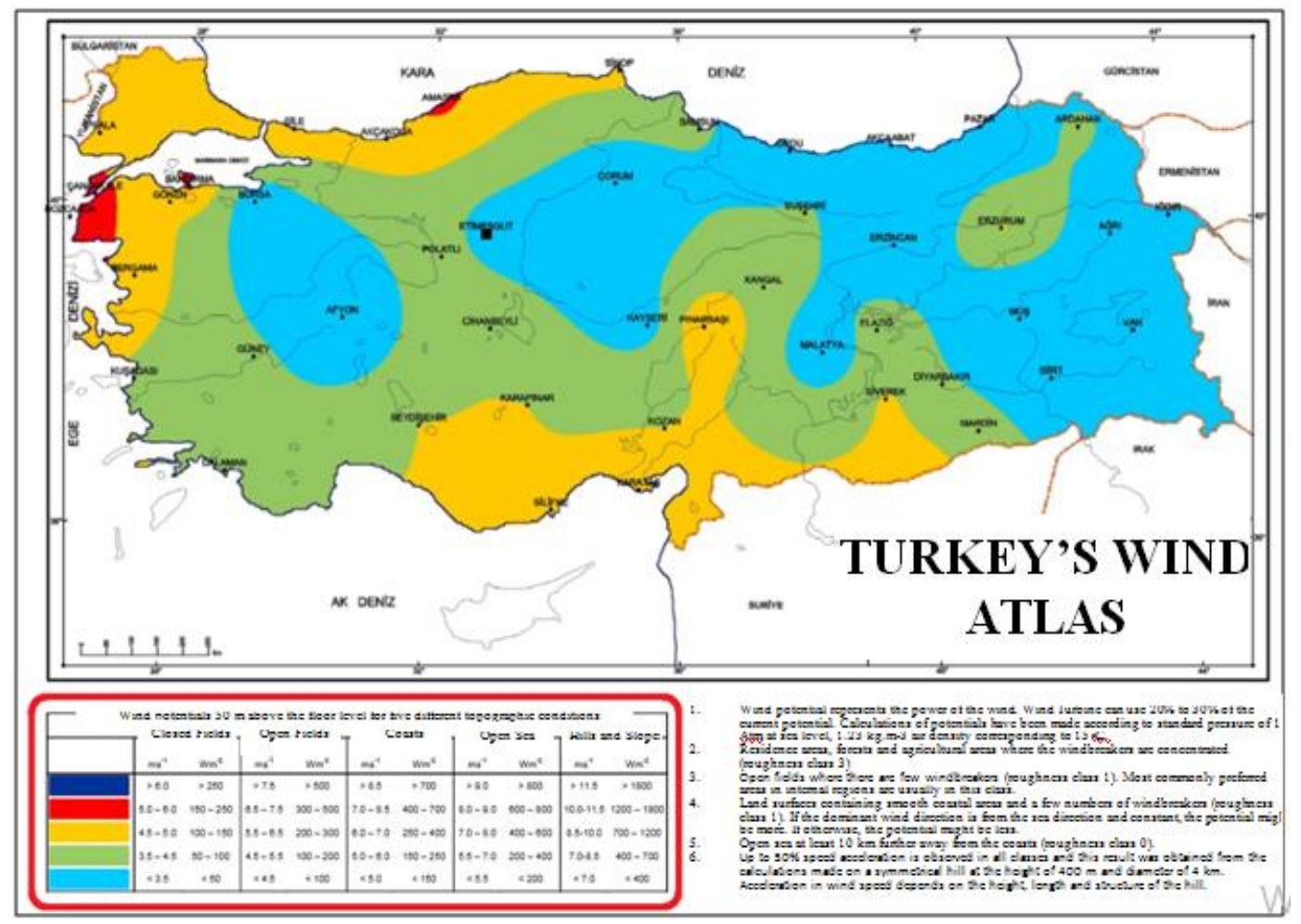

Figure 3. Turkey wind energy potential atlas [20].

In the study Matlab program designed meteorolojik_fuzz In the system, average wind speed $\mathrm{X} 1$, average power density $\mathrm{X} 2$ and capacity factor $\mathrm{X} 3$ introduction despite the values $\mathrm{Y} 1$ produces an output value. 
Meteorological based parameters It is assessed meteorolojik_fuzzy fuzzy logic model in Figure 4 , each used membership function Figure 3 for with the help of identified ranges and linguistic Variables Figure 5, Figure 6 and In Figure 7 It is shown.

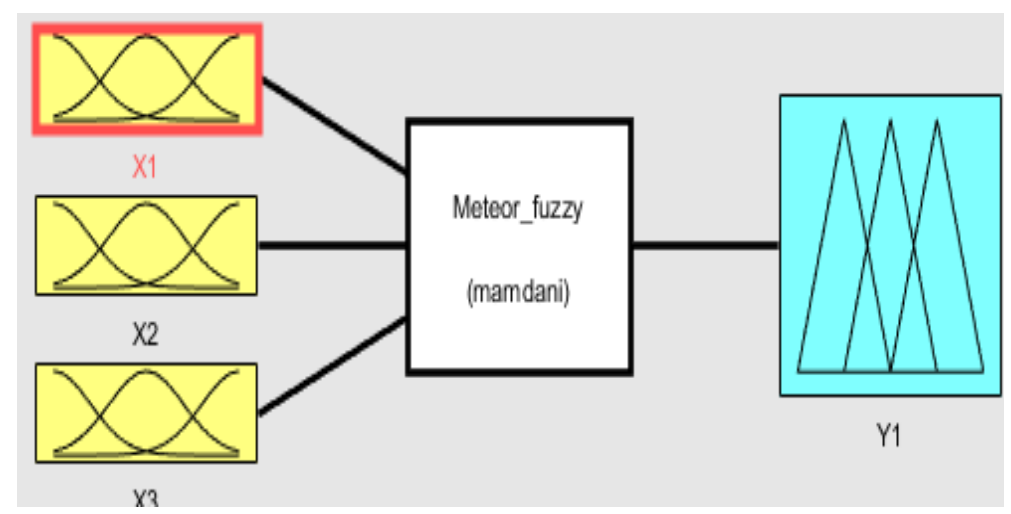

Figure 4. Meteorological fuzzy

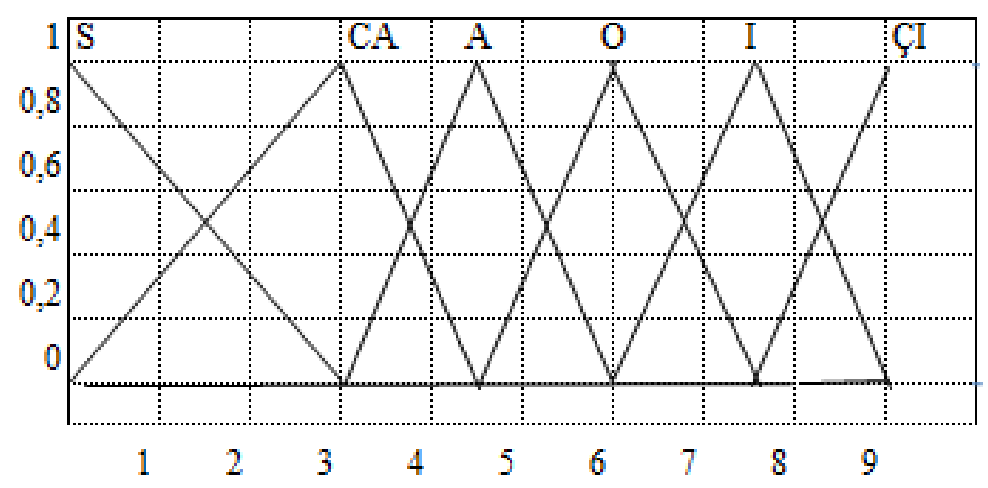

Figure 5. Average wind speed

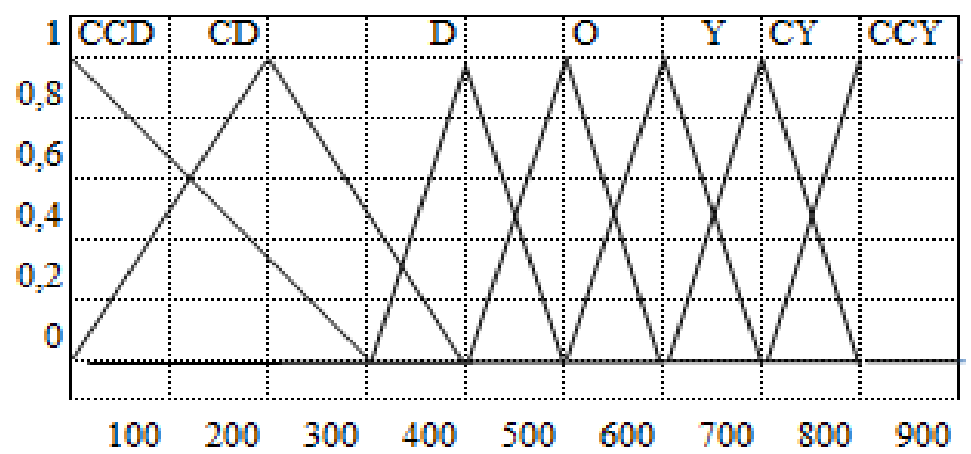

Figure 6. Average power density 


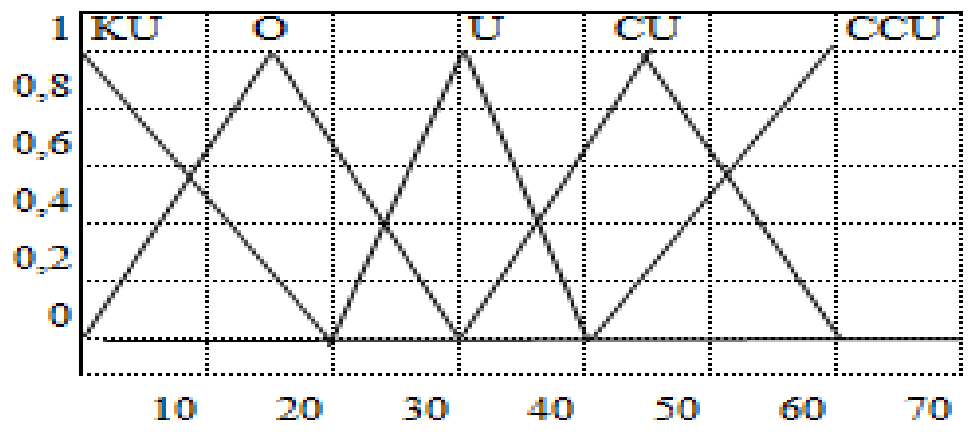

Figure 7. Capacity factor

When the wind speed and direction data obtained from the measurement stations and the power density and capacity factor values calculated through these data are examined, it is observed that there are serious accumulations above and below the specified membership function intervals.

While determining the value ranges of the membership function, the values close to these value ranges are considered to be statistically insignificant. Therefore, the correct values for the system designed by considering these accumulations determine our It is desired to calculate a flexible value range that will provide. For this, recalculation and determination of membership function value range prepared based on wind potential atlas with fuzzy $\alpha$ cutting technique will be provided.

In the sample mathematical calculation for the first value range of the average wind speed membership function in study 3 the normal value was selected and the following triangular membership function was created in the fuzzy set $\left(\begin{array}{lll}0 & 3 & 4,5\end{array}\right)$.

$\mu_{A}(x)= \begin{cases}0, & x<0 \\ \frac{x-0}{3-0}, & 0 \leq x \leq 3 \\ \frac{4,5-x}{4,5-3}, & 3 \leq x \leq 4,5 \\ 0, & x>4,5\end{cases}$

In this function, $a_{1}=0, a_{2}=3$ and $a_{3}=4,5$ are accepted and the following formulas are obtained for the neighborhood of 3 normal values.

$a_{1}^{\alpha}=3 . \alpha$

$a_{3}^{\alpha}=4,5-1,5 . \alpha$

The neighborhood values of the normal values of the intervals of the average wind speed membership function for different $\alpha$ cutting coefficients were calculated with the help of formulas 9 and 10. In the calculation, the neighborhoods obtained for the different $\alpha$ cutting coefficients and the neighborhoods corrected according to the step value being 0.025 are shown in Table 1. 
Table 1. Average wind speed membership function intervals calculated for different $\alpha$ cutting coefficients

\begin{tabular}{|c|c|c|c|c|c|c|c|c|c|c|c|c|}
\hline \multirow{2}{*}{$\begin{array}{c}\alpha \\
\text { Coofficien }\end{array}$} & \multirow[b]{2}{*}{0} & \multicolumn{5}{|c|}{ Neighbourhood of the Normal Values } & \multicolumn{6}{|c|}{ Corrected Interral } \\
\hline & & 3 & 4,5 & 6 & 7,5 & 9 & 0 & 3 & 4,5 & 6 & 7,5 & 9 \\
\hline 0,98 & $0.0,06$ & $2,99-3,03$ & $4,47-4,53$ & $5,97 \cdot 6,03$ & $7,47-7,53$ & $8,97-9,03$ & $0.0,05$ & $2,975-3,05$ & $4,50-4,575$ & $6.6,075$ & $7,425-7,55$ & $9,025-9,075$ \\
\hline 0,97 & $0.0,09$ & $2,99 \cdot 3,04$ & $4,45 \cdot 4,54$ & $5,95 \cdot 6,04$ & $7,45 \cdot 7,54$ & $8,95 \cdot 9,04$ & $0.0,075$ & $2,975 \cdot 3,05$ & $4,50-4,575$ & $5,975 \cdot 6,075$ & $0,425 \cdot 7,579$ & $9,025 \cdot 9,075$ \\
\hline 0,95 & $0.0,15$ & $2,97-3,07$ & $4,42 \cdot 4,57$ & $5,92 \cdot 6,07$ & $7,42-7,57$ & $89,92 \cdot 9,07$ & $0.0,15$ & $2,95 \cdot 3,075$ & $4,475 \cdot 4,400$ & $5,95 \cdot 6,10$ & $7,375 \cdot 7,60$ & $9,00 \cdot 9,10$ \\
\hline 0,93 & $0.0,21$ & $2,97-3,10$ & $4,39-4,60$ & $5,89-6,10$ & $7,39-7,60$ & $8,89-9,10$ & $0-0,225$ & $2,95-3,075$ & $4,475-4,65$ & $5,95-6,125]$ & $7,35-7,625$ & $8,975-9,125$ \\
\hline 0,91 & $0.0,27$ & $2,97 \cdot 3,13$ & $4,36 \cdot 4,63$ & $5,86 \cdot 6,13$ & $7,36 \cdot 7,63$ & $8,86 \cdot 9,13$ & $0.0,25$ & $2,95-3,10$ & $4,475 \cdot 4,65$ & $5,925 \cdot 6,15$ & $7,325 \cdot 7,65$ & $8,95 \cdot 9,15$ \\
\hline 0,89 & $0.0,33$ & $2,96-3,16$ & $4,33 \cdot 4,66$ & $5,83 \cdot 6,16$ & $7,33-7,66$ & $8,83 \cdot 9,16$ & $0.0,325$ & $2,925-3,125$ & $4,45-4,675$ & $5,925-6,20$ & $7,325-7,65$ & $8,925 \cdot 9,175$ \\
\hline 0,87 & $0.0,39$ & $2,96-3,19$ & $4,30-4,69$ & $5,80 \cdot 6,19$ & $7,30-7,69$ & $8,80 \cdot 9,19$ & $0.0,40$ & $2,925-3,125$ & $4,425 \cdot-4,70$ & $5,90-6,2255$ & $7,275-7,67$ & $8,925 \cdot 9,20$ \\
\hline 0,85 & $0.0,45$ & $2,95 \cdot 3,22$ & $4,27-4,72$ & $5,77 \cdot 6,22$ & $7,27 \cdot 7,72$ & $8,77 \cdot 9,22$ & $0.0,475$ & $2,90-3,15$ & $4,40-4,70$ & $5,825 \cdot 6,325$ & $7,25 \cdot 7,75$ & $3,875 \cdot 9,275$ \\
\hline 0,82 & $0.0,54$ & $2,94-3,27$ & $4,23-4,77$ & $5,73-6,27$ & $7,23-7,77$ & $8,73 \cdot 9,27$ & $0,0,575$ & $2,90-3,175$ & $4,35 \cdot-4,80$ & $5,80-6,375$ & $7,25 \cdot 7,80$ & $8,90-9,30$ \\
\hline 0,79 & $0,0,63$ & $2,93-3,31$ & $4,18 \cdot 4,81$ & $5,68 \cdot 6,31$ & $7,18-7,81$ & $8,68 \cdot 9,31$ & $0.0,625$ & $2,875 \cdot 3,20$ & $4,275 \cdot 4,85$ & $5,725 \cdot 6,457$ & $7,225 \cdot 7,87$, & $8,925 \cdot 9,325$ \\
\hline
\end{tabular}

The average power density for different $\alpha$ cut-off coefficients was calculated with the help of the 9th and 10th formulas of the normal values of the ranges of the membership function. In the calculation, the neighborhoods obtained for the different $\alpha$ cutting coefficients and the neighborhoods corrected according to the step value of 1.25 are shown in Table 2.

Table 2. Power density membership function ranges calculated for different $\alpha$ cutting coefficients

\begin{tabular}{|c|c|c|c|c|c|c|c|c|c|c|c|c|c|c|}
\hline \multirow{2}{*}{$\begin{array}{c}\alpha \\
\text { Coefficienu } \\
\\
\end{array}$} & \multicolumn{7}{|c|}{ Neighbourhood of the Normal Values } & \multicolumn{7}{|c|}{ Corrected Interval } \\
\hline & 0 & 200 & 400 & 500 & 600 & 700 & 800 & 0 & 200 & 400 & 500 & 600 & 700 & 800 \\
\hline 0,98 & $0.0,6$ & $199,6-200,4$ & $999,8.4002$ & $499,8-300,2$ & $399,8 \cdot 600,2$ & $2699,8-700,2$ & $799,8.000,2$ & $0.1,25$ & $198,75 \cdot 201,25$ & $4398,79-401,25$ & $497,5.502,5$ & $|997,5.602,5|$ & $697,5.702,5$ & $797,5.502,5$ \\
\hline 0,97 & $0.0,9$ & $199,4 \cdot 200,6$ & $999,7.400,3$ & $499,7.500$ & $399,7 \cdot 600,3$ & $699,7 \cdot 700,3$ & $799,7.800,3$ & $0.1,25$ & $198,73 \cdot 201,2$. & $5998,73.401,24$ & $497,3,502,5$ & $597,3.602,5$ & $697,5 \cdot 702,5$ & $797,3.802,5$ \\
\hline 0,95 & $0 \cdot 1,1$, & 199.201 & $399,5.400,5$ & $499,5 \cdot 500,5$ & $399,5=600,5$ & $699,5.700,5$ & $799,5 \cdot-800,5$ & 0.25 & $197,5 \cdot 202,5$ & $399,5.402,5$ & $496,25 \cdot 503,75$ & $9996,25 \cdot 603,79$ & $9696,25 \cdot 703,75$ & $996,25 \cdot 803,78$ \\
\hline 0,93 & $0.2,1$ & $198,6 \cdot 201,4$ & $399,3.400$, & $499,3 \cdot 500$, & $399,3.600$, & $6999,3.700,7$ & $799,3 \cdot 000,7$ & 0.25 & $197,5 \cdot 202,5$ & $396,25 \cdot 403,79$ & 495.505 & 595.605 & 695.705 & 795.505 \\
\hline 0,91 & 0.2 & $198,2 \cdot 201,8$ & $399,1.4009$ & $499,1 \cdot 500$, & $399,1.600,9$ & $699,1.700,9$ & $799,1.800,9$ & $0.3,75$ & $196,5 \cdot 203,75$ & $396,25 \cdot 403,79$ & $195.506,25$ & $593,75,506,28$ & $693,75 \cdot 706,25$ & $993,75 \cdot 806,25$ \\
\hline 0,89 & $0.3,3$ & $197,8 \cdot 202$, & $3989.401,1$ & 4989.501. & $6989 \cdot 601,1$ & $698,9.701,1$ & $798,9 \cdot 001,1$ & $0.3,75$ & $196,5 \cdot 203,75$ & 395.405 & $493,75 \cdot 506,25$ & $592,5 \cdot 606,25$ & $692,5 \cdot 706,25$ & $792,5 \cdot 806,25$ \\
\hline 0,87 & $0.3,9$ & $197,4 \cdot 202,6$ & $3998,7.401,3$ & $198,7 \cdot 501$, & $398,7.601,3$ & $698,7 \cdot 701,3$ & $798,7.901,3$ & $0.5,0$ & $195.203,75$ & $393,75-40,25$ & $493,75 \cdot 507,5$ & $590 \cdot 607,5$ & $691,25 \cdot 707,5$ & $791,25 \cdot 807,5$ \\
\hline 0,85 & 0.45 & 197.203 & $398,5.401,5$ & $198,5.501$. & $698,5 \cdot 601,5$ & $698,5 \cdot 701,5$ & $798,5-001,5$ & $0.5,0$ & $193,75 \cdot 205$ & $393,75 \cdot 406,22$ & $492,5 \cdot 507,5$ & $888,75.608,79$ & $690.708,75$ & $790 \cdot 808,75$ \\
\hline 0,82 & $0.5,4$ & $196,4,203,6$ & $398,2 \cdot 401,8$ & $498,2.501 .8$ & $398,2 \cdot 601,8$ & $698,2 \cdot 701,8$ & $798,2.901,8$ & $0.6,25$ & $192,5 \cdot 206,25$ & $392,5-408,75$ & $488,75 \cdot 508,75$ & $586,25 \cdot 610$ & $687,5.710$ & $787,5-810$ \\
\hline 0,79 & $0-6.3$ & $195,8-204,2$ & $3979.402,1$ & $497,9.502,1$ & $5979.602,1$ & $697,9.702,1$ & 797,9-802,1 & $0.7,5$ & $191,25 \cdot 207,5$ & $391,25 \cdot 410$ & $487,5-511,25$ & $883,75 \cdot 611,24$ & $686,25 \cdot 711,25$ & $786,25 \cdot 811,25$ \\
\hline
\end{tabular}

The neighborhood values of the normal values of the ranges of the capacity factor membership function for different $\alpha$ cutting coefficients were calculated with the help of formulas 9 and 10 . In the calculation, the neighborhoods obtained for the different $\alpha$ cutting coefficients and the neighborhoods corrected according to the step value of 0.25 are shown in Table 3 . 
Table 3. Capacity factor membership function ranges calculated for different $\alpha$ cut coefficients

\begin{tabular}{|c|c|c|c|c|c|c|c|c|c|c|}
\hline \multirow{2}{*}{$\begin{array}{c}\alpha \\
\text { Cotfficient }\end{array}$} & \multicolumn{5}{|c|}{ Neighbourhood of the Normal Values } & \multicolumn{5}{|c|}{ Conrected Interval } \\
\hline & 0 & 15 & 30 & 45 & 60 & 0 & 15 & 30 & 45 & 60 \\
\hline 0,98 & $0-0,04$ & $14,99 \cdot 15,03$ & $29,98-30,02$ & $44,97-45,03$ & $59,96-60,04$ & $0-0,25$ & $14,5-15,5$ & $29,5-30,5$ & $44,5-45,5$ & $59,5 \cdot 60,5$ \\
\hline 0,97 & $0.0,06$ & $14,98-15,04$ & $29,97-30,03$ & $44,95-45,04$ & $59,94-60,06$ & $0.0,25$ & $14,5 \cdot 15,5$ & $29,5-30,5$ & $44,5-45,5$ & $59,5 \cdot 60,5$ \\
\hline 0,95 & $0.0,1$ & $14,97 \cdot 15,07$ & $29,95-30,05$ & $44,92 \cdot 45,07$ & $39,90-60,1$ & $0,0,50$ & $14,25 \cdot 15,75$ & $29,25 \cdot 30,78$ & $44,25 \cdot 45,75$ & $39,25 \cdot 60,75$ \\
\hline 0,93 & $0.0,14$ & $14,96 \cdot 15,10$ & $29,93 \cdot 30,07$ & $44,89 \cdot 45,10$ & $59,86 \cdot 60,14$ & $0.0,50$ & $14 \cdot 15,75$ & $29 \cdot 30,75$ & $44.45,75$ & $59 \cdot 60,75$ \\
\hline 0,91 & $0=0,18$ & $14,95 \cdot 15,13$ & $29,91=30,09$ & $44,86 \cdot 45,13$ & $59,82 \cdot 60,18$ & $0.0,50$ & $13,75 \cdot 16,25$ & $28,75=31,25$ & $43,75 \cdot 46,25$ & $58,75=61,25$ \\
\hline 0,89 & $0.0,22$ & $14,94=15,16$ & $29,89 \cdot 30,11$ & $44,83 \cdot 45,16$ & $59,78 \cdot 60,22$ & $0.0,50$ & $13,5 \cdot 16,5$ & $28,5-31,5$ & $43,5 \cdot 46,5$ & $58,5=61,5$ \\
\hline 0,87 & $0.0,26$ & $14,93 \cdot 15,19$ & $29,87 \cdot 30,13$ & $44,80 \cdot 45,19$ & $59,74-60,26$ & $0.0,75$ & $13,25 \cdot 16,75$ & $28,25 \cdot 31,75$ & $43,25 \cdot 46,75$ & $58,25 \cdot 61,75$ \\
\hline 0,85 & $0.0,3$ & $14,92-15,22$ & $29,85 \cdot 30,15$ & $44,77 \cdot 45,22$ & $59,70 \cdot 60,30$ & $0.1,0$ & $13 \cdot 17$ & 28.32 & 43.47 & 58.62 \\
\hline 0,82 & $0.0,36$ & $14,91 \cdot 15,27$ & $29,82 \cdot 30,18$ & $44,73-45,27$ & $59,64-60,36$ & $0.1,5$ & $12,75-17,25$ & $27,75-32,25$ & $42,75-47,25$ & $47,75-62,25$ \\
\hline 0,79 & $0-0,42$ & $14,89 \cdot 15,31$ & $29,79-30,21$ & $44,68-45,31$ & $59,58-60,42$ & $0.2,0$ & $12,25-17,75$ & $27,25-32,75$ & $42,25-46,75$ & $47,25-62,75$ \\
\hline
\end{tabular}

\section{RESULTS AND DISCUSSION}

When the wind speed and direction data obtained from the measurement stations and the power density and capacity factor values calculated through these data are examined, it is observed that there are serious accumulations in some value ranges. Although these accumulations have a similar effect in the decision process, the determined value ranges in the applications do not include them in the decision process.

In the studies made on the data obtained in the study, the $\alpha$ coefficient that best represents the accumulation level was determined as 0.91 . As a result of the calculations, the average wind speed, average power density and the capacity factor and membership function structure and value ranges of the capacity factor are given in Figure 8, Figure 9 and Figure 10, respectively.

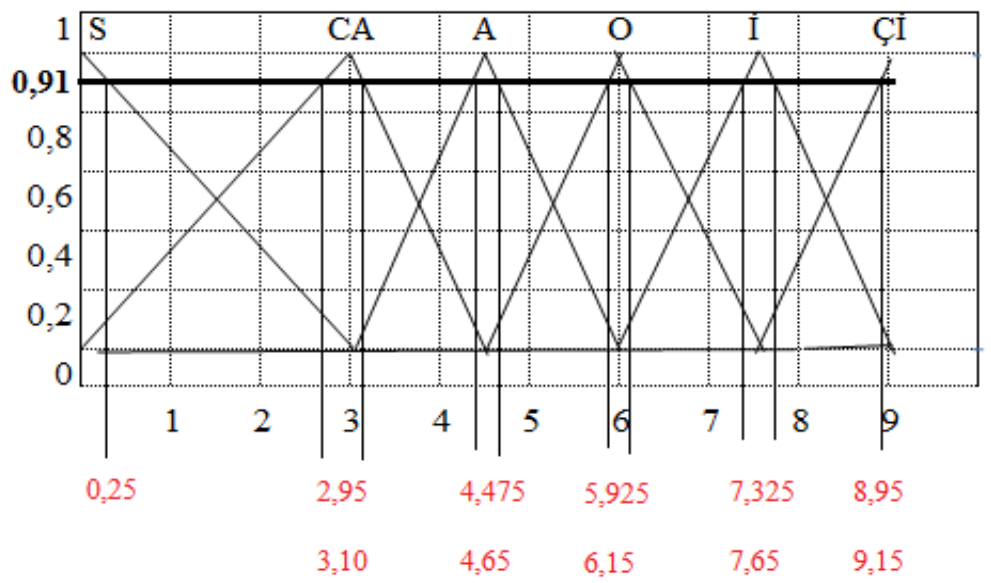

Figure 8. Average wind speed membership function defined by $\alpha$ cutting coefficient 


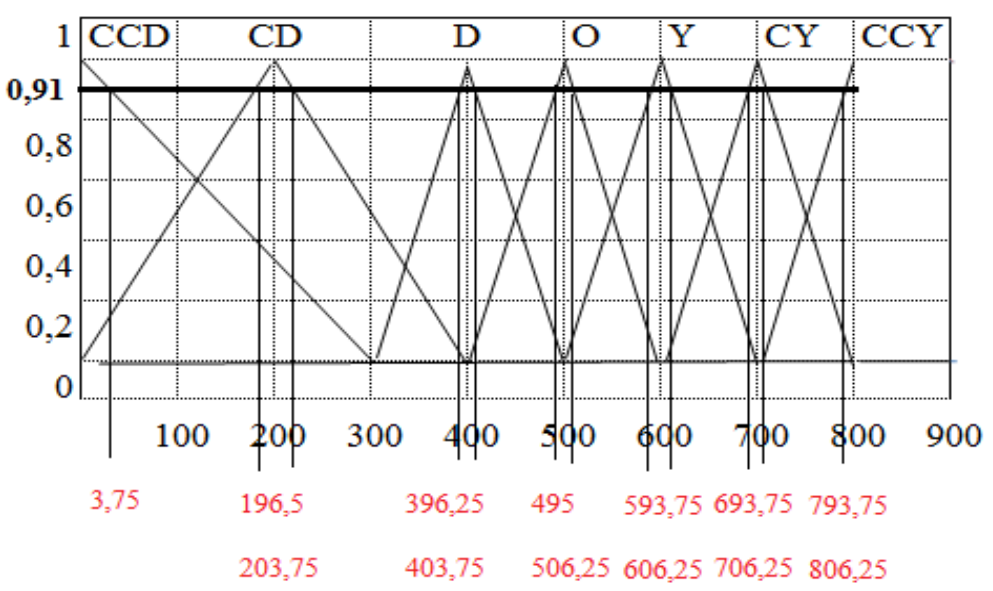

Figure 9. Average power density membership function defined by $\alpha$ cutting coefficient

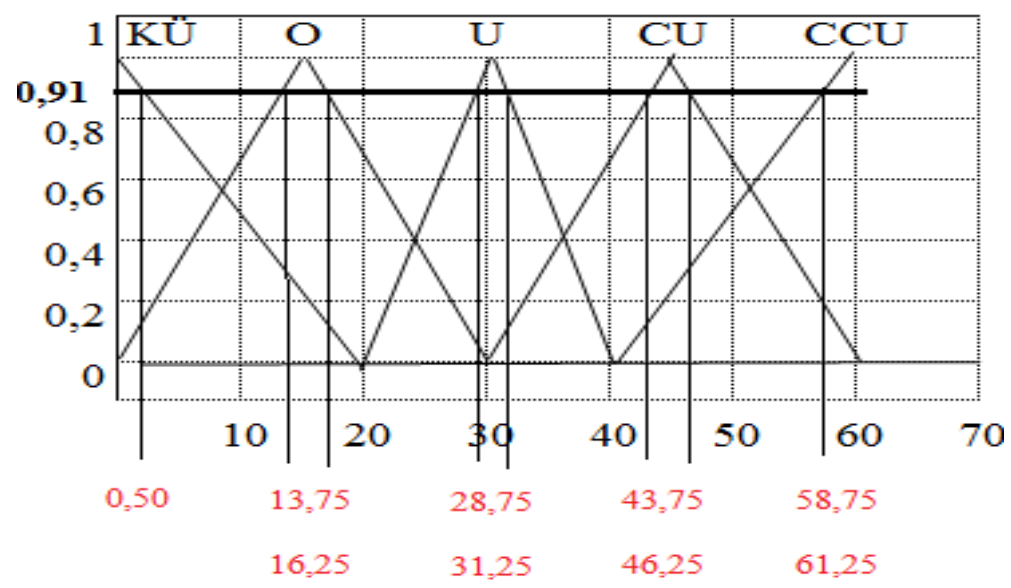

Figure 10. Capacity factor membership function defined by $\alpha$ cutting coefficient

\section{CONCLUSIONS}

In this study, the normal value neighborhoods for different $\alpha$ cutting coefficients and corrected neighborhoods for the determining step values were calculated in the wind turbine installation model determined as a dynamic process. According to the width of the accumulation around the membership functions value ranges defined for the meteorological parameters in the wind turbine model designed using these calculated tables, the appropriate $\alpha$ cut-off coefficient has been selected and thus, the most suitable value ranges have been calculated for the system designed by considering these accumulations.

As a result of the calculations, the membership functions of the average wind speed, average power density and capacity factor determined as the input value are given in Figure 11, Figure 12 and Figure 13, respectively. 


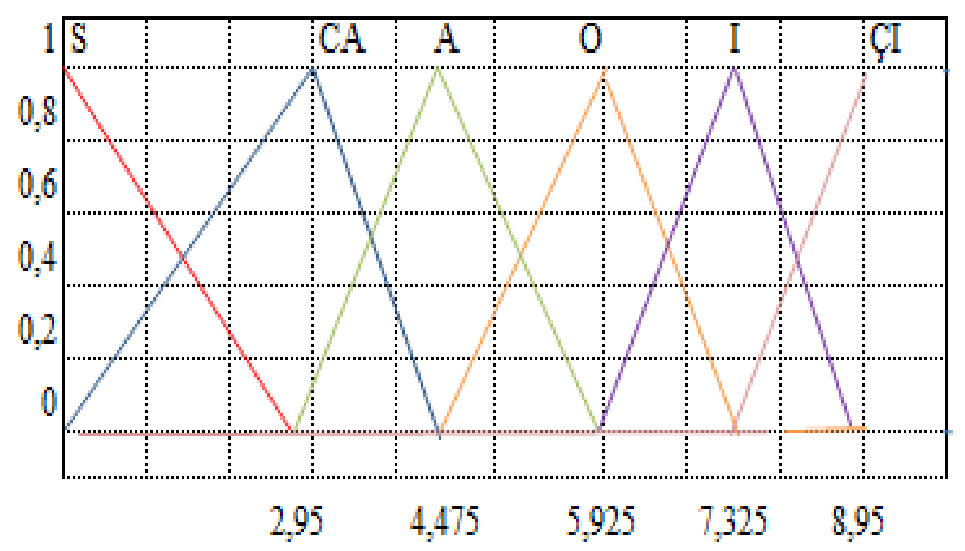

Figure 11. Calculated average wind speed

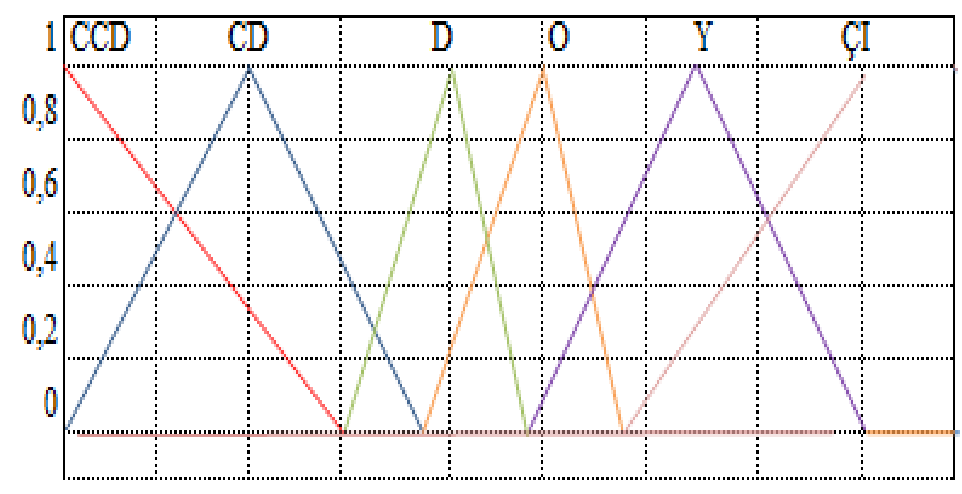

$196,5 \quad 296,25 \quad 396,25 \quad 495 \quad 593,75 \quad 693,75 \quad 793,75$

Figure 12. Calculated average power density

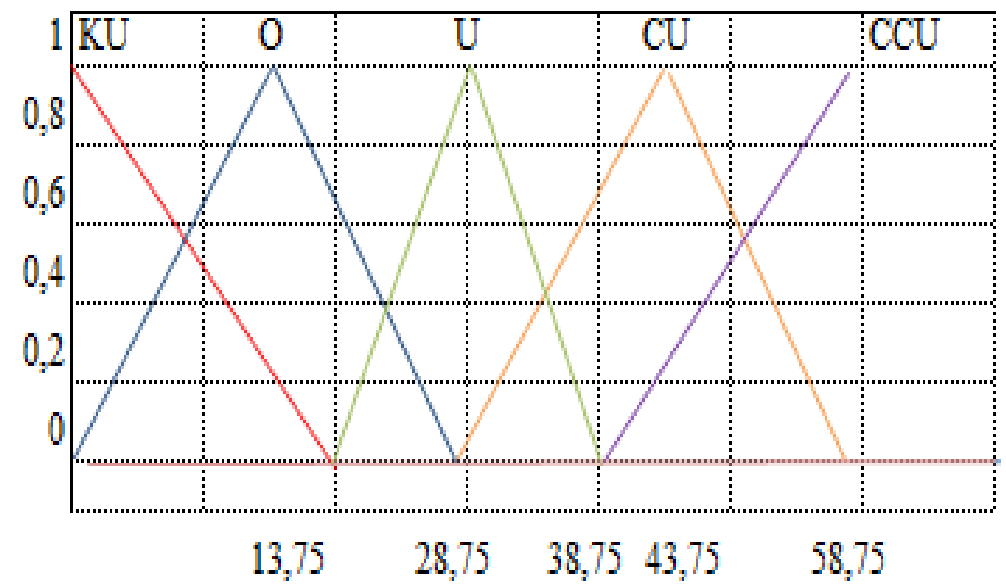

Figure 13. Calculated capacity factor

In the study, the values that serve the same purpose with the redefined membership functions were entered into the system. The findings obtained as a result of the application are intended to form a scale that will be based on the studies to be carried out for the wind power plant installation problem. 


\section{REFERENCES}

[1] Kandil, A., El-Tantawy, O.A., El-Sheikh, S.A., El-Sayed, Sawsan S.S. (2017). Fuzzy soft connected sets in fuzzy soft topological spaces II, Journal of the Egyptian Mathematical Society, 25, 171-177.

[2] Alan, A.Y. (2003). Nispi Mantik (Fuzzy Logic), International Seminar Group, Ludwigshaven, Germany

[3] Kissi, M., Ramdani, M., Tollabi, M. and Zakarya, D. (2004). Determination of fuzzy logic membership functions using genetic algorithms: application to structure-odor modeling, Journal of Molecular Modeling, 10 (56): $335-341$.

[4] Kim, J.W., Kim, B.M. and Kim, J.Y. (1998). Genetic algorithm simulation approach to determine membership functions of fuzzy traffic controller, Electronics Letters, 34 (20): 1982- 1983.

[5] Mondelli, G., Castellano, G., Attolico, V. and Distante, C. (1998). Parallel genetic evolution of membership functions and rules for a fuzzy controller, High-Performance Computing and Networking Lecture Notes in Computer Science, 1401, 922-924.

[6] Kim, J.H., Seo, J.Y. and Kim, G.C. (1996). Estimating membership functions in a fuzzy network model for part-of-speech tagging, Journal of Intelligent \& Fuzzy Systems, 4 (4): 309-320.

[7] Singpurwalla, N.D. (2004). Membership functions and probability measures of fuzzy ets - Rejoinder, Journal of the American Statistical Association, 99 (467): 884-889.

[8] Lindley, D.V. (2004). Membership functions and probability measures of fuzzy sets - Comment, Journal of the American Statistical Association, 99 (467): 877-879.

[9] Simon, D. (2002). Sum normal optimization of fuzzy membership functions, International Journal of Uncertainty fuzziness and Knowledge-Based Systems, 10 (4): 363-384.

[10] Sancho-Royo, A. and Verdegay, J.L. (1999). Methods for the construction of membership functions, International Journal of Intelligent Systems, 14 (12): 1213-1230.

[11] Chen, S.M., Kao, C.H. and Yu, C.H. (2002). Generating fuzzy rules from training data containing noise for handling classification problem, Cybernetics and Systems, 33 (7): 723-748.

[12] Cho, Y., Lee, K., Yoo, J. and Park, M. (1998). Autogeneration of fuzzy rules and membership functions for fuzzy modelling using rough set theory, IEE Proceedings-Control Theory and Applications, 145 (5): 437-442.

[13] Lin, C.J. and Ho, W.H. (2005). An asymmetrysimilarity- measure-based neural fuzzy inference system, Fuzzy Sets and Systems, 152 (3): 535- 551.

[14] Wu, T.P. and Chen, S.M. (1999). A new method for constructing membership functions and fuzzy rules from training examples, IEEE Transactions on Systems Man and Cybernetics Part B-Cybernetics, 29 (1): 25-40.

[15] Halgamuge, S.K., Poechmueller, W. and Glesner, M. (1995). An alternative approach for generation of membership functions and fuzzy rules based on radial and cubic basis functions networks, International Journal of Approximate Reasoning, 12 (3-4): 279-298.

[16] Abebe, A. J., GUINOT, V. and Solomatine, D. P. (2000). Fuzzy alpha-cut vs. Monte Carlo techniques in assessing uncertainty in model parameters, Proc. 4-th International Conference on Hydroinformatics, Iowa City, USA.

[17] Turnbull, H. and Omenzetter, P. (2017). Fuzzy finite element model updating of a laboratory wind turbine blade for structural modification detection, Procedia Engineering, 199, 2274-2281.

[18] Bojadziev, G. and Bojadziev, M. (1991). Fuzzy Sets, Fuzzy Logic, Applications, World Scientific, London.

[19] Bai, Y. and Wang, D. (2006). Fundamentals of Fuzzy Logic Kontrol Fuzzy Sets, Fuzzy Rules and Defuzzifications, Advanced Fuzzy Logic Technologies InIndustrial Applications, Springer.

[20] Internet: General Directorate of Meteorology, (2017). https://www.mgm.gov.tr/genel/ruzgar-atlasi.aspx 